\title{
Modernidad en movimiento. Cómo enfrentarse a la movilidad motorizada en Teherán, Santiago y Copenhague
}

\begin{abstract}
The progress of modernization is accompanied by an emphasis on urban mobility and economic growth together with increasing environmental awareness. This article aims at analysing the transformation of transport systems (car-road system and public transport) together with related urban changes and their societal effects in three very different cities: Santiago, Tehran and Copenhagen. In these cities vehicle ownership is increasing and motorized mobility is further facilitated. Mass motorization is an essential part of modernization. However, its impact on societal development is an area of research that has received little attention. Moreover, mass motorization is handled in different ways in different socio-political settings. In Tehran the emphasis is on technological upgrading and enlargement. In Santiago, an important re-regulation and modernisation of the systems is taking place. In Copenhagen all kinds of improvements are made partly inspired by the Agenda 21 . Furthermore, as this article points out, the local political order and chosen strategies to handle motorization problems are diverse. My analysis emphasizes mass motorization, political interventions, civil society, urban governance, sustainable development and the management of urban mobility. I conclude that political strength at the city level seems to be weaker than what is observed at the national level.
\end{abstract}

Keywords: urban traffic, sustainable mobility, transport policies, Tehran, public deliberation, Santiago de Chile, Copenhagen.

\section{Resumen}

El progreso de la modernización está acompañado por un énfasis en la movilidad urbana y el crecimiento económico, junto con un creciente conocimiento medioambiental. Este artículo tiene como objetivo analizar la transformación de los sistemas de transporte (automotriz y de transporte público) junto con cambios urbanos relacionados, y sus efectos sociales en tres ciudades muy diferentes: Santiago, Teherán y Copenhague. En estas ciudades, la propiedad de vehículos se está incrementando y la movilidad motorizada se está además facilitando. La motorización masiva es una parte esencial de la modernización. Sin embargo, su impacto en el desarrollo social es un área de investigación que ha recibido escasa atención. Además, la motorización masiva es manejada de maneras diferentes, en distintos escenarios socio-políticos. En Teherán el énfasis está puesto en el mejoramiento y ampliación tecnológicos. En Santiago, una importante re-regulación y modernización del sistema está teniendo lugar. En Copenhague, todos los tipos de mejoramiento son realizados inspirados en parte en la Agenda 21. Además, como precisa el artículo, el orden político local y las estrategias escogidas para manejar los problemas de la motorización son diversos. Nuestro análisis enfatiza la motorización masiva, las intervenciones políícas, la sociedad civil, el gobierno urbano, el desarrollo sustentable y la administración de la movilidad urbana. Se concluye que la fuerza política a nivel de la ciudad parece ser más débil de lo que se observa a nivel nacional.

Palabras clave: tránsito urbano, movilidad sustentable, políticas de transporte, deliberación pública, Teherán, Santiago de Chile, Copenhague. 


\section{Introducción. La nueva agenda de políticas de transporte. La administración de la modernización del transporte urbano}

$\mathrm{N}$ uestro futuro común está amenazado por el deterioro medioambiental (p. ej. cambio climático), por problemas políticos (p. ej. terrorismo) y sociales (p. ej. marginalización de amplios grupos urbanos). A escala global, una extensión "incontrolada" en el mercado de la movilidad motorizada ha sido seguida por un emergente reconocimiento de los problemas asociados a la cultura del automóvil. En muchas ciudades, la eficiencia en el sistema de tránsito está decayendo junto con la expansión urbana y el crecimiento y movilidad de la población. Las infraestructuras están congestionadas debido al incremento vehicular. Hay numerosas contradicciones ligadas al continuo aumento de la movilidad motorizada. Por una parte, es claro que este incremento contribuye al deterioro medioambiental y otros efectos secundarios negativos, como las lesiones causadas por accidentes de tránsito y el ruido. Por otra parte, la nueva infraestructura y el mayor transporte están relacionados con importantes alternativas para dar solución a las problemáticas del subdesarrollo, a través del progreso económico y el avance técnico. Además, las tendencias actuales de la globalización económica interactúan con la modernización urbana.

El propósito final de este estudio ha sido la búsqueda de alternativas viables para administrar el transporte sustentable en áreas urbanas. Queríamos saber si los cambios sociales y medioambientales han abierto o no una nueva ventana de posibilidades relacionadas con alternativas para mejorar el transporte urbano. ¿Las estrategias adoptadas están ligadas a interpretaciones locales de las dificultades del tránsito y a percepciones -también locales- sobre cómo manejar estos problemas, o son expresiones de visiones tradicionales dominantes acerca del rol de la motorización de masas en las ciudades modernas?

* Department of Peace and Development Research, Göteborg University. E-mail: marie.thynell@padrigu.gu.se.

** "Modernity on the move. How to cope with motorized mobility in Tehran, Santiago and Copenhagen". Traducido por Diego Campos. Recibido el 28 de febrero de 2005, aprobado el 11 de julio de 2005.
¿Cuál es el carácter de las intervenciones políticas para conducir estos problemas?

Hasta ahora, los cientistas sociales han tenido un lugar secundario en relación con la elaboración de políticas de transporte. En su lugar, los conductores han sido los economistas y profesionales del transporte. Esta relación refleja las visiones establecidas para confrontar los problemas de tránsito, a saber, con el énfasis puesto en la expansión del sistema de transporte y/o en el mejoremiento tecnológico. Un desafío contemporáneo es integrar el desarrollo sustentable con políticas de movilidad urbana, e incrementar la sustentabilidad de la sociedad entera. Por tanto, esta aproximación está guiada por la perspectiva del usuario, y por cómo promover una movilidad sustentable que comprenda una sustentabilidad social. Todo esto es parte de un movimiento regulatorio para manejar los efectos secundarios negativos de las crecientes actividades de negocios en el sector del transporte. Está también relacionado con la idea de que la planificación de las necesidades de movilidad de toda la población es una conditio sine qua non para administrar el desarrollo de la sociedad (Thynell, 2004). El papel de la ciencia social es contribuir con una perspectiva de la vida urbana, y el punto de partida es que las políticas de transporte deben reflejar el cambio social (empleo, vivienda, estructura familiar y cambios demográficos).

Desde la perspectiva de la ciencia social, la manera de estudiar los viajes comienza en el nivel macro, con el foco puesto en la relación Estado-mercado. Argumentamos que las estructuras establecidas relacionadas con la comprensión hegemónica de la movilidad motorizada han moldeado el resultado de estas estructuras (educación, puntos de vista profesionales, intereses vinculados a los negocios). Estas estructuras sociales básicas han pugnado por continuas inversiones en la forma tradicional de manejar la movilidad física en las ciudades, a menudo por medio de sistemas viales extendidos orientados al automóvil: más puentes, túneles y autopistas. Nuestro punto de vista es que el uso incremental de vehículos motorizados necesita ser administrado y regulado en orden a reducir la desigual distribución de recursos y deterioro medioambiental asociados con la movilidad de las personas. Hasta ahora, los cambios en las visiones establecidas en el sector del transporte urbano han ocurrido lentamente. El desarro- 
llo y el transporte sustentables bien pueden ser descritos como parte de las estructuras establecidas y de las formas tradicionales de manejar el desarrollo social, como se discutirá más adelante.

\subsection{Aproximación teórica}

En orden a enfatizar la relación Estado-mercado en el análisis de las tres ciudades, buscamos inspiración en Karl Polanyi. En su libro La gran transformación (1957), se presenta una distinción entre las sociedades tradicionales, la evolución de la sociedad de mercado (la sociedad liberal) y la emergencia de los Estados reguladores y protectores (Estados de bienestar, Estados socialistas). Encontramos relevante el reutilizar su aproximación con relación al sector del transporte, y transferir sus conceptos para analizar la descontrolada extensión del mercado dentro del campo de la motorización seguida por la emergencia de las regulaciones.

Polanyi desarrolló la noción de "doble movimiento", refiriéndose a las ondas del crecimiento del mercado y las regulaciones protectoras, respectivamente. Desde esta perspectiva, el "primer movimiento" se refiere a la globalización de la motorización conducida por el mercado, y el "segundo movimiento", a las intervenciones políticas para regular y limitar los efectos de las actividades de mercado provocados por el "primer movimiento". Los contenidos del "segundo movimiento" son expresados como regulaciones diseñadas por un régimen político en un determinado momento, para proteger a la sociedad de los efectos secundarios de la motorización. Por consiguiente, hay cuatro elementos en juego: el mercado y el Estado, y los problemas percibidos y las medidas escogidas. La interacción entre los numerosos intereses en el sector del tránsito urbano tiene lugar a nivel de la ciudad, así como en los niveles correspondientes al Estado y las familias. Este artículo incluye sólo un análisis tentativo de esta perspectiva.

\subsection{Selección de las tres ciudades}

En orden a responder las preguntas de investigación específicas, fueron necesarios algunos principios-guía para la selección de las ciudades. Teherán, Santiago y Copenhague son ciudades capitales en países de riqueza y recursos considerables. Fueron escogidas en tanto representan una amplia variedad de gobiernos urbanos, relaciones Estado-mercado y características políticas y socio-culturales. Copenhague ejemplifica las políticas de un viejo Estado de bienestar y elementos de transporte sustentable. Santiago es conocida en todo el mundo por estar gobernada por políticas económicas liberales. Teherán es la capital de una nación islámica que sigue políticas de gobierno fundamentalistas. Por ende, en estas ciudades difieren los trasfondos político y económico (estructuras sociales), así como el carácter de los actores actuales (la forma del agenciamiento).

\subsection{Metodología}

Los casos estudiados están basados en estudios bibliográficos de documentos, información oral y entrevistas (personales y de otro tipo) realizadas por correo electrónico. Visitamos las ciudades y viajamos en transporte público: buses, metro, taxis legales y automóviles privados. Además de varias entrevistas con profesionales destacados, discutimos sobre movilidad en encuentros callejeros con la gente. La recolección de información para este artículo se completó en 2003. Consecuentemente, algunos eventos posteriores de relevancia, como por ejemplo el Transantiago, no son discutidos.

En Santiago se pudo encontrar con facilidad abundante información y entrevistados. Numerosos estudios sobre transporte y literatura relevante estaban disponibles. A pesar de esto, no encontramos estudios acerca del comportamiento y actitudes en viaje de los usuarios, acerca de cambios sociales (por ejemplo, que reflejaran el género o preferencias de los usuarios) o de comportamientos del transporte. Tampoco encontramos evaluaciones de los cambios en las políticas o de intervenciones anteriores.

El material recolectado sobre Teherán tuvo un carácter diferente, dado que no pudimos realizar entrevistas formales mientras estuvimos allí. Hubo que buscar investigaciones y documentos oficiales acerca de las condiciones del tránsito, comportamientos de los usuarios y temas de política pública. Las fuentes escritas e información estadística sobre Teherán escaseaban. Sin embargo, visitamos importantes organizaciones y tuvimos encuentros con investigadores. Por consiguiente, la validez requerida pudo ser asegurada de manera aceptable. 
Recapitulando el trabajo de investigación, encontramos que hemos recolectado más información y nos hemos centrado mucho más en Teherán, de modo de compensar las dificultades iniciales. Este esfuerzo fue hecho a costas del estudio en Copenhague. Aquí la información fue fácilmente accesible, e incluyó además datos sobre comportamientos en viaje, pero no sobre perspectivas de género o actitudes de los usuarios. El acceso a la información relativa a los flujos de tránsito en diferentes partes de Copenhague, en distintos momentos, fue también bastante bueno. Fue más problemático encontrar información acerca de la forma en que los hogares responden a los cambios en el sistema de transporte, o acerca de los cambios dentro de las familias (empleo, familias más grandes, etc.). La información sobre el comportamiento en viaje de di- versos grupos socio-económicos fue particularmente difícil de encontrar en Teherán y en Santiago.

En términos generales, fue posible encontrar información sobre los niveles macro y urbano en las tres ciudades. Esto incluye información acerca de inversiones, préstamos, flotas de vehículos, nuevos vehículos, número de buses públicos, pasajeros y viajes. Nuestra impresión es que el comportamiento en viaje de la mayoría de las personas es discutido en términos generales, y rara vez en términos específicos. La necesidad de los economistas por información altamente agregada parece dominar todavía la construcción del conocimiento sobre el tránsito urbano. Por lo tanto, las formas económicas socialmente construidas para entender la movilidad moderna continúan prevaleciendo en la toma de decisiones respecto de las políticas de tránsito urbano.

Tabla 1. Información básica sobre Teherán, Santiago y Copenhague.

\begin{tabular}{|c|c|c|c|}
\hline & Teherán & Santiago & Copenhague \\
\hline Sistema político & República presidencialista & República presidencialista & Monarquía presidencialista \\
\hline Gobierno & $\begin{array}{l}\text { Conservador, } \\
\text { fundamentalista }\end{array}$ & $\begin{array}{l}\text { Coalición socialista- } \\
\text { demócrata cristiana, } \\
\text { apoyada por populistas } \\
\text { de derecha }\end{array}$ & Coalición centro-derecha \\
\hline Deliberación pública & No & No & Sí \\
\hline $\begin{array}{l}\text { Población metropolitana } \\
\text { (millones) }\end{array}$ & 16 & $6^{1}$ & 2,5 \\
\hline Densidad área urbana & 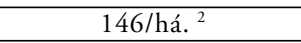 & $7.167^{3}$ & 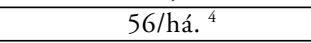 \\
\hline PIB per cápita (dólares) ${ }^{5}$ & 2.473 & 5.856 & 44.929 \\
\hline $\begin{array}{l}\text { Automóviles/1.000 } \\
\text { habitantes }\end{array}$ & 180 & 110 & $210^{6}$ \\
\hline Buses público/privados & 9.000 & 7.800 & 1.100 \\
\hline Metro & Sí & Sí & Sí \\
\hline Tarificación por congestión & Sí & No & No \\
\hline Políticas pro-bicicleta & Sí (experimental) & Sí & Sí \\
\hline $\begin{array}{l}\text { Mitigación de la } \\
\text { contaminación del aire }\end{array}$ & Sí & Sí & Sí \\
\hline Producción automotriz & $\mathrm{Si}^{7}$ & No & No \\
\hline Producción de petróleo & $\mathrm{Si}^{8}$ & No & No \\
\hline
\end{tabular}

\footnotetext{
${ }^{1}$ Gobierno de Chile, Censo 2002.

${ }^{2}$ Este dato es la densidad de la ciudad de Teherán. La población actual de la ciudad de Teherán está estimada en 7,6 millones de personas.

${ }^{3}$ Gran Santiago. Gobierno de Chile, Censo 2002.

${ }^{4}$ Este dato es la densidad de la ciudad de Copenhague, usualmente referido al centro de la ciudad, con una población total de 0,5 (City of Copenhagen, 2001).
} 


\section{El caso de Teherán}

\subsection{Introducción}

Teherán es una de las 24 megaciudades del mundo. Es una ciudad mundial y la capital de Irán, que tiene aproximadamente 70 millones de habitantes. Irán es el segundo productor de petróleo más grande de la OPEC, y tiene las segundas reservas más grandes de gas natural. Teherán ha experimentado dos revoluciones en menos de 40 años. Ambas han implicado sustanciales cambios económicos, así como completas transformaciones políticas, religiosas y socio-económicas 9

La historia reciente de Teherán ha sido, así, afectada por dos revoluciones. La "primera revolución" se refiere a los cambios constitucionales a comienzos del siglo 20, pero también a las transformaciones sociales y económicas durante el gobierno del Shah Reza (1941-1979). Durante su mandato la modernización fue asociada con la occidentalización - por ejemplo en el rediseño de la ciudad capital. En Teherán, el mejoramiento del transporte y las comunicaciones fue visto como algo más importante que el abastecimiento de electricidad y agua en las casas. Se construyeron nuevas avenidas atravesando áreas caracterizadas por construcciones tradicionales, y se impusieron nuevas arterias para favorecer las oportunidades de comunicación y negocios. En consecuencia, los callejones, pasajes estrechos $-k o c h e h-y$ casas típicas fueron reemplazados. Otro de los objetivos políticos fue "reconstruir Irán a imagen de Occidente" (Abrahamian, 1982, p. 140). Se introdujo un nuevo mercado de suelo y propiedad, y por primera vez la economía de mercado se extendió al espacio urbano.

La expresión "segunda revolución" se refiere a la introducción de una constitución islámica en 1979. Consecuentemente, las virtudes políticas fueron cambiadas. Por ejemplo, el fomento de la privacidad por

\footnotetext{
${ }^{9}$ Esta visión de la importancia de Teherán contrasta con la percepción de la misma como parte de un grupo de ciudades que tiene "mínima evidencia" de mundialidad (Sassen, 2002). Esta sugerencia es contradicha también por Mandanipour (1998), quien sostiene que "el control de grandes reservas de petróleo y su influencia política y cultural en Medio Oriente y Asia Central le han dado [a Teherán] el estatus de ciudad mundial semi-periférica" (p. 25).
}

oposición a la apertura y la vida pública pasó a ser algo importante. Por lo tanto, en Teherán comenzaron a prevalecer las condiciones para otro desarrollo, distinto al común en las democracias liberales. Inmediatamente después de la revolución, los automóviles fueron percibidos como "cosas satánicas" ${ }^{10}$. Durante muchos años, la forma estadounidense o hegemónica de desarrollar el sistema de transporte por medio del automóvil privado no fue aceptada. Por un breve periodo de tiempo, el transporte público fue apoyado, y durante los primeros años de la revolución islámica, existió otra forma, local, de interpretar la complejidad del tránsito urbano y el transporte. El modo de vida occidental moderno fue rechazado, incluyendo toda la cultura del automóvil, a través de la adopción de una estrategia anti-occidental (Thynell, 2003). Esta estrategia fue más tarde reemplazada cuando Irán retornó a una política amistosa hacia el automóvil ${ }^{11}$.

En 2003, la vida en Teherán estaba basada en valores sociales y religiosos y un orden político diferentes a los de las sociedades liberales (un orden fundamentalista, musulmán shiíta). Esta fundación social y religiosa se reflejaba en los comportamientos en viaje, los modos preferidos de viajar y las conductas en los espacios públicos. Ello no obstante, la cultura del automóvil era fuerte. En 2003, el sector automotriz era el de más rápido crecimiento (correspondiendo a un 30\% del PIB, de acuerdo al Tehran Times). Esta expansión era estimulada por el combustible subsidiado, que costaba 9 centavos de dólar por litro ${ }^{12}$, probablemente el más barato del mundo.

\subsection{Estructura fisica de Teherán}

La ciudad de Teherán se expande rápidamente en todas direcciones. Las áreas residenciales más apetecidas están localizadas en la zona montañosa del

\footnotetext{
${ }^{10}$ Los automóviles eran vistos como "vehículos satánicos que llevaban a sus pasajeros al infierno".

${ }^{11}$ Entre los países donde la propiedad o utilización del automóvil ha sido restringida por razones económicas o políticas se cuentan Noruega, Albania, China, Japón y las antiguas repúblicas soviéticas, junto con países de Europa central.

${ }^{12}$ www.International-Fuel-Prices.com (datos de noviembre de 2004).
} 
norte, y las áreas industriales y residenciales populares, en la parte seca y llana en el sur-este. Aquí es también donde se ubican las refinerías de petróleo y otras industrias mecánicas. Así, la brisa proveniente de la zona desértica lleva el aire contaminado de la parte industrial a las laderas montañosas de Teherán, donde hay menos viento. En la ciudad, la contaminación es de las peores del mundo, y se cree que el $80 \%$ de las emisiones provienen de los vehículos y fuentes móviles, mientras que el resto se debe a las 8.500 plantas industriales. El país entero tiene aproximadamente 6 millones de automóviles. $\mathrm{Mu}$ chos de ellos son antiguos o de bajos estándares técnicos. El Paykan, de producción doméstica, es el automóvil más común, y de él se dice que no respeta las restricciones medioambientales cuando es producido ni cuando es conducido ${ }^{13}$.

En 2003, la población de la Gran Teherán (que incluye la ciudad vecina de Karaj, con otros 4 millones de habitantes), se estimaba en alrededor de 16 millones ${ }^{14}$. Una urbanización muy rápida produjo una necesidad incontrolable de viviendas y de consumo, así como un extendido desempleo, deterioro de los estándares de vida, densidad de población ylo que resulta de particular interés para este estudioun incremento dramático de la demanda por movilidad física.

En Teherán, la ciudad vieja -con divisiones sociales muy estrictas- ha pasado por varios cambios físicos. Los principales proyectos de modernización fueron realizados en los años '30, cuando se removieron las doce puertas y entradas antiguas a la ciudad. Por la misma época, las nuevas calles se transformaron en arterias principales de transporte, y las plazas en rotondas. Estas plazas habían sido tradicionalmente espacios para peatones, pero la gente tuvo que hacerle lugar a los vehículos. Esta re-planificación influenció además los comportamientos sociales, dado que el antiguo diseño que acentuaba las partes interiores y menos visibles de las casas hacia sus traspatios, fue reemplazado por un énfasis en las

\footnotetext{
${ }^{13}$ En 1964 comenzó el ensamblaje del fabricante nacional de automóviles, Paykan. Durante los'70 el Shah utilizó un lema deseando "un Paykan para cada iraní".

${ }^{14}$ Aproximadamente $30 \%$ de la población total tenía entre 0 y 14 años en 2003.
}

características exteriores de éstas ${ }^{15}$. El rediseño incluyó los espacios abiertos para formas de vida occidentales. Nuevos comportamientos sociales, como un incremento en la movilidad individual, y estilos de vida modernos acompañaron estos cambios físicos. El producto socio-cultural se transformó en una mixtura compuesta por estilos de vida existentes y tradicionales. Se debe agregar que una vasta mayoría de los habitantes de Teherán migraron desde pequeños pueblos, áreas rurales y otras culturas. Hablaban idiomas extranjeros y pertenecían a otros grupos religiosos y étnicos. Esta mezcla cultural ha tenido un impacto en la relación con los sistemas socio-tecnológicos como el transporte, así como en la manera en que las calles han sido utilizadas ${ }^{16}$.

\subsection{El tránsito en Teherán}

En 2003 había casi 3 millones de vehículos registrados, incluyendo 730.000 motocicletas y 370.000 camionetas, junto con otros tipos de vehículos (TCTTS, 2002). Sin embargo, el número actual de automóviles en Teherán es probablemente mucho más alto, dado que los conductores llevan a la ciudad vehículos registrados en las provincias. En los diarios se puede encontrar a menudo titulares afirmando que diariamente dos mil automóviles son llevados a Teherán. De acuerdo a estimaciones realizadas por la TCTTS en 1995, aproximadamente el $60 \%$ de la población urbana no poseía automóvil. La misma fuente sostenía que "mientras gran parte de la población de las familias decrece y la tasa de vehículos por familia aumenta, se incrementa el ingreso per cápita y la tasa de viajes vehiculares" (TCTTS, 2002, p. 6).

Entre 1996 y 2001, el número de viajes creció un $10 \%$ (TCTTS, 2002). Con el fin de evitar los

15 "A través de la imposición de un nuevo sistema de caminos, calles amplias y arborizadas intersectando en ángulos rectos sobre el viejo tejido urbano, se modificó el espacio urbano de acuerdo con las demandas por mayor movilidad. Fue en parte para romper con la estructura social existente, su heterogeneidad comunal alojada en un sistema ortogonal, que una red de nuevas calles fue trazada para atravesar muchas áreas urbanas a lo largo del país, incluyendo la muy importante ciudad capital" (Madanipour 1998, p. 40).

${ }^{16}$ Los farsi son el grupo étnico más grande, estimados en un $38 \%$. Además del idioma oficial farsi, Irán es multilingüe. 
efectos secundarios más severos (embotellamientos constantes, reparaciones costosas, etc.), era común llamar a un radio taxi o buscar un taxi ilegal, o bien salir con los amigos en un solo automóvil. Este para-tránsito o mercado de transporte comercial parecía crecer con rapidez. No obstante, no fue posible encontrar ninguna información estadística al respecto que fuera confiable. Sin embargo, el uso de taxis sin licencia fue identificado como uno de los factores causantes de dificultades crecientes en la ciudad; ya en 1997 el número de taxis sin licencia se estimaba en 40.000, y la mayor parte del transporte público en Teherán es realizado por este tipo de vehículos, que operan usualmente sobre una base part-time. La movilidad individual se incrementó anualmente un 3\%, y el número de automóviles lo hizo en 8\% durante 1993-1995. Este último año, de acuerdo con la TCTTS, se realizaron 11.500 .000 viajes diarios ${ }^{17}$. En 2001, el habitante de Teherán promedio realizó 1,6 viajes diarios en algún tipo de vehículo (TCTTS, 2002). Se calcula que los hombres realizan dos viajes diarios, y las mujeres uno. En 2002 la compañía de transporte público operaba 5.356 buses y 3.753 mini-buses. Hoy en día, varios cientos de miles de commuters entran y salen diariamente de Teherán (alrededor de un 5\% de los habitantes del área de Teherán), en condiciones de tránsito caóticas.

\subsection{Algunas observaciones sobre el caso de Teherán}

En Teherán, el primer movimiento expansivo tuvo un ímpetu impresionante. La ciudad estaba creciendo rápidamente, junto con la necesidad por movilidad física. La información disponible da la imagen de una feroz motorización masiva. Buscando restringir sólo al tránsito "esencial” la entrada al centro de la ciudad, se introdujo en 1981 una zona medioambiental que cubría un área de 23 kilómetros cuadrados (TCTTS, 2002).

En Teherán, los mismos valores básicos de modernidad prevalecieron en grupos socio-económicos pudientes, tal como en los países occidentales, sintetizados en términos de libertad, movilidad, velocidad, individualismo, poder y privacidad. También parece haber una misma comprensión acerca del rol del transporte en el desarrollo general, como en to-

\footnotetext{
${ }^{17}$ Considero irreal el número total de viajes. Las estimaciones para 2001 fueron las mismas (TCTTS, 2002).
}

das partes. En Teherán, la regulación de ciertos comportamientos sociales era bastante estricta, en marcado contraste con la desobediencia en el tránsito, y con el hecho de que las conductas de conducción descontrolada no eran perseguidas o castigadas. Por tanto, el número de accidentes y víctimas fatales era muy alto. Al mismo tiempo, los "escuadrones del vicio" controlaban otros tipos de comportamientos sociales en espacios públicos, y controlaban también la vida social en los hogares. Mujeres y hombres eran severamente castigados en caso de que no actuaran de acuerdo con las normas oficialmente establecidas.

La globalización de los mercados tuvo una importante relación con las ampliaciones de las infraestructuras, pero parece haber tenido una influencia menor en la implementación de políticas de fomento a la sustentabilidad. El transporte público fue mejorado por medio de nuevas líneas de metro y otras iniciativas, pero se hicieron necesarias muchas más acciones en relación con la gran demanda de viajes. El transporte sustentable no es un objetivo importante en Teherán. Los diversos cuerpos que controlan el tránsito y el transporte estaban mal coordinados, y no contribuían mucho a la creación de un segundo movimiento eficiente y protector, capaz de regular la demanda de transporte y las dificultades del tránsito. El mejoramiento tecnológico en colaboración con socios asiáticos era percibido como un eficiente medio para manejar las problemáticas del transporte, como la extensión del metro, e importantes programas para mitigar las emisiones contaminadoras del aire han sido llevados a cabo junto con colaboradores extranjeros (suecos, japoneses, etc.).

\section{El caso de Santiago de Chile}

\subsection{Introducción}

Los procesos paralelos de globalización económica y democratización han tenido repercusiones en el desarrollo urbano. Esto es evidente en Santiago de Chile. Esta es una ciudad mundial que está poniendo al día su administración urbana. Desde los años '70, Chile ha tenido dos tipos diferentes de órdenes políticos, con un gobierno actual en acusado contraste con el régimen militar de Pinochet (1973-1990). La administración urbana desregulada de los '80 condujo a un tránsito urbano 
distorsionado, y la infraestructura no fue mejorada ni extendida. El transporte público fue claramente dejado de lado por las autoridades públicas, y un gran número de empresarios competían por incrementar sus ganancias.

Siendo un país pequeño con una economía abierta, Chile ha sido siempre sensible al desarrollo del comercio internacional. En 2001 la tasa de inversión era seis veces más alta que en 1990 (The World Bank, 2001). En 2002, el 32\% de los préstamos realizados al país por el Banco Mundial se dirigieron al sector transporte ${ }^{18}$. Las contribuciones públicas destinadas a este sector jugaron un papel muy limitado.

Chile ha sido bien conocido por su altamente desigual distribución del ingreso. Entre 1985 y 1998 , la pobreza se redujo fuertemente, y la economía creció un 7,4\% anual en promedio (Sperling y O’Ryan, 2002). Pero a pesar de este notable crecimiento, persisten las desigualdades económicas ${ }^{19}$.

La modernización en Chile continuó siendo conducida por la liberalización económica. El gobierno democrático y las estrategias basadas en el mercado constituyeron el marco para guiar la administración urbana y para dar forma a la nueva política de transportes. También tuvo lugar una importante modernización de los sistemas de electricidad y alcantarillado, basada en la iniciativa pública y privada. Estos cambios estuvieron relacionados con nuevas políticas en el sector del transporte y con un nuevo plan para el transporte urbano en Santiago, como se indica más adelante ${ }^{20}$. De este modo, el atractivo de Santiago se acrecienta, y mientras tienen lugar estos cambios, lo local y la calidad de vida de las ciudades se transforman en un importante factor en la atracción de capital global, el cual determina quién gana y quién pierde en el juego global. Esto tiene importantes implicancias para el desarrollo urbano sustentable y para la reducción del tránsito.

\footnotetext{
${ }^{18}$ Ver http://lnweb18.worldbank.org/external/lac/ lac.nsf/Countries/Chile.

19 En 2003, de acuerdo a The World Bank (2001), $17 \%$ era de la población era pobre (sobreviviendo con menos de 3 dólares diarios), y $4 \%$ vivía en extrema pobreza (menos de 1,5 dólares diario).

${ }^{20}$ Chile está altamente urbanizado. $86,3 \%$ de los chilenos viven en áreas urbanas (The World Bank, 2001).
}

En 1994, el transporte sustentable fue identificado como un objetivo relevante, y se creó la Comisión Nacional del Medio Ambiente. En Chile esta institución es lo más cercano a un "ministerio del medioambiente", sin serlo en realidad. En 1998 se creó el Plan de Prevención y Descontaminación. El continuo crecimiento y las nuevas políticas en Chile han llamado la atención; por tanto, era tiempo de descubrir una nueva ventana de posibilidades en relación con el transporte urbano. Se levantaron las siguientes preguntas de investigación: ¿qué tipo de regulaciones fueron desarrolladas, y cómo respondieron a ellas los usuarios y el mercado? ¿Qué fue identificado como políticas de transporte urbano viables en Santiago?

\subsection{El tránsito en Santiago}

El área del Gran Santiago tiene aproximadamente 5,5 millones de habitantes, distribuidos en $1 \mathrm{mi}-$ llón y medio de hogares (SECTRA, 2003). Tanto la urbanización como la expansión urbana han sido intensas, estimuladas por el fuerte crecimiento económico. Este crecimiento ha sido seguido por un espectacular aumento en el número de vehículos, excediendo el $10 \%$ anual (Sperling y O'Ryan, 2002). El número de viajes realizados en automóviles se ha más que triplicado durante 1991-2001.

En 2002 había 860.000 automóviles privados en Santiago; en otras palabras, cerca de la mitad de los hogares tenía uno. El sistema de transporte de Santiago consiste en 8.000 buses y 3 líneas de metro (40 kilómetros) ${ }^{21}$. Había 50.000 taxis, lo que equivale a un taxi por cada 100 habitantes. Había también taxis que seguían rutas especiales, compartidos por 4-6 personas. Se trataba de un tipo legal de para-tránsito que operaba 150 rutas: los llamados "taxis-colectivos", todos los cuales eran de propiedad privada y operaban en rutas licenciadas.

La población, la urbanización y el crecimiento económico han provocado un rápido incremento en el transporte ${ }^{22}$. Durante los días hábiles se reali-

${ }^{21}$ En diciembre de 2005 se inauguró el primer tramo de la línea 4 del Metro de Santiago (N. del E.).

${ }^{22}$ En 1996, 7,6\% de todos los viajes se hicieron en automóviles privados, menos que en Irán en aquel momento. Los automóviles privados se han incrementado desde 20 por cada 1.000 habitantes en 1966, a 60 en 1977, y luego a 110 en 1996 (O’Ryan y Turrentine, 2000). 
zan 16,3 millones de viajes, más de dos tercios de los cuales se llevan a cabo a través de medios motorizados. El transporte público ha perdido cerca de un tercio de todos los viajes, y los automóviles privados han incrementado el número de sus viajes los días hábiles. Actualmente, el $42 \%$ de todos los viajes motorizados se realiza en automóvil, el $38 \%$ en buses públicos y el $7 \%$ en metro. Pero la tenencia de automóviles en Chile es aún baja en comparación con los países europeos.

La desigual distribución del ingreso se reflejaba en el patrón de transporte de Santiago. En el segmento de altos ingresos, el 69\% de los viajes totales se realizaba en automóvil, el $8 \%$ en bus, el $10 \%$ a pie y el $6 \%$ en metro. En el grupo de bajos ingresos, el 13\% de los viajes se hacía en automóvil, el 29\% en bus, el $45 \%$ a pie y sólo el $3 \%$ en metro. En total, el $64 \%$ de los viajes totales se realizaba en bus, caminando o en bicicleta, pero las inversiones en infraestructura no reflejaban bien este comportamiento de los viajes ${ }^{23}$. La mayor parte de éstas se realizó en las siete nuevas autopistas y en extensiones de metro.

\subsection{Algunas observaciones sobre el caso de Santiago}

La actividad dominante fue la implementación del nuevo plan Transantiago, consistente en un nuevo cuerpo de acciones coordinadas ${ }^{24}$ cuyo objetivo era modernizar el sistema de transporte público en términos de eficiencia, medioambiente, organización y aspectos legales. El nuevo plan fue bien recibido y se transformó en parte del programa presidencial 2000-2006. Aparentemente, hubo consenso político en torno al plan. Las mejoras planificadas cubrían la mayor parte de los aspectos de la movilidad, como la seguridad, eficiencia, velocidad, autosustentación económica, sustentabilidad social y medioambiental, y se consideró además que se reducirían las emisiones de gases. Pero el plan enfrentó muchas dificultades y se pospuso un año. Este plan mostró además cómo el gobierno respondía a la anterior desregulación y a una economía crecientemente globalizada, así como a la meta adoptada del desarrollo sustentable. La regulación y reorganización del

\footnotetext{
${ }^{23}$ Ver nota 11.

${ }^{24}$ Transantiago coordina al Comité de Ministros para el Transporte de Santiago, organismo creado por decreto presidencial durante el 2003.
}

transporte (el segundo movimiento de Polanyi) tuvo lugar "naturalmente", cuando las disfuncionalidades del tránsito incrementaron los costos de las lesiones, así como la lentitud de los flujos de tránsito y la congestión. Para hacer frente a este escenario se consideraron dos estrategias principales. La primera consistió en tomar el control de la ciudad, fortaleciendo el gobierno y los sistemas públicos de transporte, y la segunda, en modernizar la ciudad e incrementar el atractivo de Santiago. En 2003, los políticos trabajaron activamente para echar a andar el plan Transantiago, parte del cual consistía en negociar préstamos para mejorar la infraestructura, y el gobierno actual presionó por la optimización de la infraestructura de transporte. No obstante, no se facilitó la coordinación entre los 34 municipios del Gran Santiago, lo que permaneció como uno de los principales problemas.

A pesar del hecho de que Santiago es famoso por buscar soluciones de mercado a los complejos problemas del transporte urbano, la tarificación por congestión no fue considerada como una opción. En 2003, ninguno de los entrevistados, investigadores o demás personas con quienes discutimos creían que ésta tenía futuro en Santiago (a diferencia, por ejemplo, de los peajes callejeros en Oslo y Londres).

Las estrategias basadas en el mercado parecieron satisfacer principalmente a los usuarios viales más acaudalados, a expensas de las necesidades de los pasajeros de bajos ingresos. Por ejemplo, las necesidades de viaje de los pobres o los escolares no recibieron la misma atención que el creciente número de propietarios de automóviles de clase media. Las familias más pobres no poseían automóviles, y viajaban menos en metro y en "colectivos" 25 . En 2003 los servicios de transporte para usuarios vulnerables como los adultos mayores estaban aún en malas condiciones, incluyendo dificultades para andar en metro y en buses públicos. Estos últimos eran percibidos como sucios e inseguros. Los conductores "se detenían en casa esquina” y no eran bien vistos por sus pasajeros. Había muchas quejas, y dado que las personas estaban buscando otras formas de

${ }^{25}$ En Chile, el 5\% más rico de la población viaja distancias 40 veces más largas que el $20 \%$ más pobre. El 1\% más rico de los chilenos viaja distancias 62 veces más largas que el 20\% más pobre (SECTRA, 2003). 
realizar sus viajes, estos buses estaban perdiendo viajeros.

Los usuarios viales más acomodados no sólo viajan mucho más; también se benefician de las costosas inversiones en infraestructura y utilizan mucha más energía que el usuario vial promedio. De acuerdo con varios de los entrevistados, la fuerza política y social de los propietarios de automóviles infringe las medidas orientadas a la sustentabilidad en la ciudad. Sin embargo, sobre esto hay visiones en conflicto.

Las ONG fueron bastante críticas hacia la implementación de las políticas adoptadas. Ellas apuntaban también a las contradicciones del plan, tales como el hecho de que tres autopistas estén siendo construidas en la ciudad ${ }^{26}$. Hasta donde sabemos, el potencial de los usuarios para adoptar un "comportamiento de transporte sustentable" no ha sido examinado o explorado adecuadamente. En 2003, los niveles familiar y urbano no interactuaban de la manera en que la ciudad y el nivel nacional parecían hacerlo.

Sin embargo, la capacidad construida fue incrementada sustancialmente, de acuerdo con la información recogida sobre las relaciones de transporte. Además, los aspectos tecnológicos del sistema de transporte fueron mejorados sustancialmente, y se construyeron importantes extensiones viales $\mathrm{y} f \mathrm{fe}$ rroviarias. La infraestructura fue construida y operada por compañías privadas que obtienen beneficios a través de los cobros realizados (peajes, en el caso de las vías). Pero la administración, cuando buscaba formas de controlar y guiar el sector del transporte, enfrentaba a menudo la cólera de los empresarios; el control político parecía ser bastante fuerte, y emergían así los conflictos con la comunidad de negocios, los empresarios de los buses y también los usuarios. Los políticos trataron de balancear los intereses, pero como en todas partes, algunos actores económicos fueron más influyentes que otros. Las circunstancias especiales relacionadas con la expansión en la infraestructura de Santiago levantaron un cierto número de temas acerca de un segundo movimiento regulatorio y protector, y también acerca del carácter

\footnotetext{
${ }^{26}$ Dos de éstas ya fueron inauguradas (N. del E.).
}

de las intervenciones políticas. Otros comentaristas fueron críticos acerca de lo que ellos identificaban como políticas nacionales poco transparentes, respecto de intereses inmobiliarios privados y de corrupción vinculada a la expansión urbana de Santiago. En relación con esta materia, la falta de audiencias públicas y de transparencia en el proceso de planificación fue vista como un déficit democrático.

\section{El caso de Copenhague}

\subsection{Introducción}

Dinamarca es una de las más antiguas y estables democracias en el mundo, y es también miembro de la Unión Europea. El país es un Estado de bienestar conocido por su participación pública, y en 2002, su ingreso per cápita era de 32.532 dólares, uno de los más altos del mundo ${ }^{27}$.

Copenhague es una ciudad antigua, originalmente un puerto que comenzó a crecer hasta ser una ciudad hace 900 años. Pero Copenhague no es sólo la capital de Dinamarca, sino además la capital medioambiental de Europa, nominada por la Agencia Ambiental Europea ${ }^{28}$. La introducción de la noción de "sustentabilidad", luego de la publicación del Reporte de la Comisión Brundtland, resultó en la creación de un plan gubernamental para el medioambiente y el desarrollo ya en 1988 (Tengström, 1999). Copenhague es una ciudad representativa de la ambición de extender la democracia y la preocupación mediambiental a la planificación del tránsito y el desarrollo de políticas de transporte.

En 1990 se presentó un nuevo plan de transporte. Comparado con planes anteriores, éste fue visto como un "documento radical" (Bögelund $e t$ al., 2002). El primer plan de tránsito y medioambiente para el centro de Copenhague se estableció en 1997. En aquel momento (y también

\footnotetext{
${ }^{27}$ Según datos del Swedish Institute of International Affairs.

${ }^{28}$ La tarea principal de la European Environment Agency es proporcionar a los decisores la información necesaria para realizar políticas sensatas y efectivas para proteger el medio ambiente y dar apoyo al desarrollo sustentable.
} 
en 2003), la contaminación del aire era considerada el problema ambiental más serio de Dinamarca. Esto significa que Dinamarca y Copenhague, como ciudad capital, se transformaron en precursoras de la modernización ecológica ${ }^{29}$. Consecuentemente, este es uno de los pocos países donde la noción de desarrollo sustentable es parte de las estructuras establecidas y se encuentra integrada en varios sectores de la sociedad.

Los planes regionales para la Gran Copenhague han estado basados en una estructura general coherente con la estructura común del centro urbano (Ministry of the Environment, 2002). El plan urbano de Copenhague, también llamado Finger Plan, fue adoptado en $1947 \mathrm{y}$ considerado moderno y funcional. En la Gran Copenhague hay 800.000 hogares. En 2000 se estableció un cuerpo de transporte regional, la Autoridad de la Gran Copenhague. Se trataba de un nuevo cuerpo político para fortalecer el área de Copenhague dentro de la Unión Europea y para facilitar la integración del transporte con el continente europeo. Actualmente, la región de Copenhague se ha expandido y su área externa incluye además ciudadanos suecos, en la cercana ciudad región de Malmö, con un total de 2,5 millones de personas. La integración física de Dinamarca con la Unión Europea le ha dado a Copenhague el rol de reducir parte de la creciente presión del transporte en el corazón de Europa.

La ciudad tiene una buena economía. Las relaciones estructurales han trabajado juntas con actividades orientadas al comportamiento sustentable. Pero hay también actores dominantes cuyas estrategias impiden el logro de la sustentabilidad. Desde la perspectiva del doble movimiento de Polanyi, la ciudad de Copenhague es un caso de gran relevancia. Por tanto, fue interesante ver cómo los políticos interpretaban su mandato y las características de los planes que han tratado de implementar. Dado que Copenhague es una de las pocas ciudades mundiales donde se ha aplicado la deliberación pública, era también interesante indagar en las actitudes de los

\footnotetext{
${ }^{29}$ Los investigadores en ciencia política han aplicado el concepto de "modernización ecológica", refiriéndose a una herramienta analítica consistente en: actuación económica, habilidad estratégica, capacidad de innovación y habilidad para el consenso (Lundquist, 1996).
}

votantes y de los movimientos sociales en relación con las regulaciones. ¿Se consideraban a sí mismos como parte de los decisores de política o no? ¿Es tal el ímpetu de la motorización masiva que finalmente las intervenciones políticas llegarán a su fin? ¿La necesidad individual de movilidad es más fuerte que la voluntad política para regular la movilidad motorizada?

\subsection{El tránsito en Copenhague}

La política declarada era asegurar el funcionamiento del sistema de transporte, disminuyendo el nivel de emisiones y deteniendo el aumento de los viajes en automóvil, en orden a incrementar el transporte sustentable. El principal objetivo de la política de transporte era hacer operativas otras medidas de corto plazo en relación con los buses públicos, y estimular los modos de transporte no motorizados, como la caminata y la bicicleta. Históricamente, Copenhague ha tenido una baja tasa de vehículos motorizados: 500.000 personas viven en el centro de la ciudad, y la propiedad de automóviles es de sólo alrededor de 210 por cada 1.000 habitantes. Así, la densidad de población y de automóviles son bajas, pero esta última está aumentando.

Debido al débil desarrollo económico durante parte de los '70 y ' 80 , la cantidad de pasajeros y automóviles se mantuvo en un nivel constante. Esta es una de las razones por las cuales la gente siguió utilizando bicicletas. En 2003, alrededor del 50\% de los viajes en el centro de la ciudad fueron realizados en bicicleta, así como el 34\% de los viajes al trabajo. Una de las calles peatonales llamada Ströget se inauguró hace 40 años. En 2003, Copenhague tenía 5,5 kilómetros de galerías peatonales, y alrededor de $6 \%$ de los viajes al trabajo se hacía a pie.

Sin embargo, los incrementos económicos y demográficos durante los ' 90 condujeron a cambios en el comportamiento de los viajes. En 2003, las familias más jóvenes y acomodadas que vivían en el centro de la ciudad hicieron más viajes en automóvil que antes. El commuting aumentó, y se hicieron más y más largos viajes. Los viajes de tipo commuter se incrementaron un 23\%, y el tránsito lo hizo un 15\% entre 1995 y 2000 (City of Copenhagen, 2001). En el área central, alrededor de un $27 \%$ de los viajes al trabajo se hicieron en transporte público 
(Københavns Kommune, 2002). Consecuentemente, se realizaron grandes inversiones en infraestructura, en autopistas de circunvalación y estacionamientos. Se hicieron además costosas inversiones en dos líneas de metro, y se planearon dos más, incluyendo un total de 27 estaciones. A pesar de estas mejoras, el número de viajes realizados en transporte público ha disminuido. La expansión urbana y la ya baja densidad de población implican que la longitud de los viajes aumentará, dificultando las formas tradicionales no motorizadas de viajar. Pero hasta ahora, y no obstante los altos ingresos y un clima bastante frío y lluvioso, el número de usuarios no motorizados se estaba incrementando.

La seguridad vial fue mejorada durante muchos años. El número de lesionados y muertos en las vías en Copenhague central (incluyendo Fredriksberg) era bajo, 986 personas en 2001. El objetivo de la seguridad vial es reducir las lesiones graves un $40 \%$ antes de 2012. En 2002, 18 personas murieron en accidentes de tránsito: 5 automovilistas, 4 ciclistas y 5 peatones, 3 motociclistas y un ciclomotorista ${ }^{30}$. Copenhague ha sido exitosa en el desarrollo relacionado con el tránsito en la ciudad. Sin embargo, en 2003, el creciente tránsito automovilístico y los problemas de estacionamiento creaban congestión. Desde 1991, la velocidad promedio de los automóviles se ha reducido un $15 \%$ en la ciudad. Es de destacar que el Consejo de Transportes, establecido en 1992 para apoyar las políticas de transporte, fue cerrado en 2002. La investigación danesa sobre transporte perdió sus posibilidades básicas para analizar y entregar conocimiento a los decisores. La resolución de cerrar el Consejo fue tomada por el nuevo gobierno, descrito como una coalición de centro-derecha apoyada por populistas de derecha.

\subsection{Algunas observaciones sobre el caso de Copenhague}

La temprana introducción de calles peatonales hace 40 años fue el comienzo del segundo movimiento regulatorio en Copenhague central. En comparación con otras ciudades, el control del tránsito tiene una larga historia en la capital danesa; en contraste con otras ciudades que hemos estudiado, la

${ }^{30}$ Ver http://www.vejpark.kk.dk/byenstrafik/sikkerhed/ tra_uheld_2002.htm. intervención y regulación del sistema de transporte comenzó antes de la intensificación de la globalización económica. Esto puede indicar que las medidas regulatorias fueron apoyadas por la sociedad civil, localmente arraigadas y menos impuestas desde arriba que en otras ciudades. Luego del comienzo de la noción de sustentabilidad en varios niveles y en la planificación, en Copenhague el segundo movimiento devino más elaborado en los' 90. La modernización de la ciudad y los cambios sociales de la época hicieron posible optar por un nuevo tipo de política de transporte, en lugar del "embrollo usual" (Lindblom, 1977). En Copenhague, el primer y segundo movimiento se han desarrollado en paralelo, por lo que el resultado fue un grado mayor de protección de los efectos secundarios que lo habitual. La sociedad civil ha sido presentada en el desarrollo de los dos movimientos como votantes o como usuarios, o bien se ha organizado en redes y movimientos sociales. Ello no obstante, ha habido algunos proyectos de tránsito que no han tenido éxito. Una de las ONG reclamaba que había habido un déficit democrático en relación con grandes decisiones de infraestructura; en otras palabras, que en algún momento del proceso el público dejó de participar. A nivel urbano, había visiones polarizadas acerca de los planes de transporte. A pesar de la fase regulatoria desarrollada, la crítica proveniente de las ONG era muy áspera. Éstas sostenían que predominaron las visiones de los actores poderosos, y que las visiones menos técnicas y populares no fueron tomadas en cuenta. En resumen, se afirmó que las deliberaciones públicas se acabaron cuando los procesos populares fueron sobrepasados por intereses económicos y políticos más poderosos.

Otras interpretaciones apuntan a que en Dinamarca está teniendo lugar una fuerte consolidación de la democracia, y que ese temprano debate acerca de la política de transporte no involucró al público del modo en que lo había hecho los últimos 15 años. El conocimiento generalizado sobre los efectos secundarios de la motorización se ha acrecentado, ypor ejemplo- las expectativas acerca del aire limpio se han incrementado, en relación con la situación de hace veinte años. Los efectos secundarios son hoy menos aceptados que antes. La movilidad automotriz masiva está llegando a una crisis, y el público general se está quejando más a menudo, indicando 
que se quiere obtener una mayor influencia en el carácter de la motorización masiva.

Las amplias construcciones de infraestructura, como el aeropuerto de Kastrup, el nuevo puente construido a Suecia, Öresundsbron, y el nuevo metro, fueron vistos por las autoridades como símbolos importantes de un gobierno regional exitoso y de progreso económico. Los esfuerzos de los planificadores han creado deliberadamente una ciudad con más calidad de vida, buscando un cierto tipo de "análisis de la vida". El objetivo era lograr que las familias con niños vivieran en el centro de la ciudad. Incrementar el atractivo del centro era una vía para hacer que las familias se quedaran ahí, y para contribuir a un aumento de su riqueza. La elaboración de estrategias para las bicicletas, los peatones y los estacionamientos fueron alternativas para hacer mejorar la calidad de vida del centro de la ciudad. Copenhague parecía seguir el camino de la mundialidad con una positiva imagen de la vida urbana. Este camino estaba guiado y controlado por los políticos, y apoyado por -y dependiente de- los negocios. De acuerdo con los planificadores entrevistados, estas inversiones han contribuido a atraer negocios y a estimular el crecimiento económico. Hoy el área de Copenhague se está expandiendo en términos del ingreso promedio, el número de automóviles privados $\mathrm{y}$ habitantes.

Desde una perspectiva global y europea, el transporte urbano en Copenhague parece bien administrado y controlado. Los cambios estructurales de los ' 80 y'90 hicieron posible el desarrollo de un transporte urbano local. El continuo desarrollo de regulaciones del segundo movimiento fue desafiado por el continuo incremento de vehículos en el centro de la ciudad. Hasta ahora, no se ha desarrollado una estrategia sólida para confrontar este problema. En Copenhague, luego de décadas de regulaciones, el futuro del transporte sustentable es un tema abierto y disputado.

\section{Discusión sobre la agenda de movilidad en Teherán, Santiago y Copenhague}

Los incrementos en la demanda de movilidad en estas tres ciudades enfatizan el papel tradicional del transporte en el crecimiento económico. Las ciudades seleccionadas eran (y todavía lo son) muy diferentes, atendiendo a las relaciones estructurales básicas como población y densidad, niveles de ingreso, desigualdades socio-económicas, autoridades públicas y gobiernos urbanos. Se pudo así encontrar que se habían adoptado tres formas diferentes de dirigir la motorización masiva.

El nivel nacional tiene la capacidad de decidir acerca de las políticas para reducir, por ejemplo, la contaminación del aire. En las ciudades, la mitigación de la contaminación atmosférica era importante y se habían establecido programas al respecto. Debe tenerse en cuenta que los tres casos corresponden a capitales y ciudades globales, y usualmente la interacción entre el nivel nacional y el urbano es más intensa en ciudades importantes como éstas. Pero en el nivel urbano, la administración a menudo carece de fuerza para realizar acciones eficientes e implementar las decisiones del gobierno. Además, toma tiempo y voluntad política el coordinar acciones para implementar políticas nacionales. A pesar de ello hay una relación cercana (a veces conflictiva) entre los niveles nacional y urbano, debido al carácter vertical de la política de transporte y el rol social del transporte en el incremento del crecimiento económico.

Esto contrasta con la relación entre los niveles familiar y urbano. El nivel urbano no parece tomar en serio las necesidades de grupos diversos de usuarios, con la excepción de algunos más fuertes (a menudo los más acomodados propietarios de automóviles). Se hacen esfuerzos para mejorar los sistemas de transporte, pero se dirigen menos de estos esfuerzos a entender el punto de vista del usuario. Una de las experiencias de investigación fue que las políticas, mejoras técnicas y otros no suelen ser evaluados desde la perspectiva de los diferentes grupos de usuarios. Los cambios en los sistemas de transporte eran vistos a menudo como adelantos en las ciudades, contribuyendo a la actualización de la tecnología y al incremento de instalaciones modernas, oferta de viajes y comodidad. Por ende, la preocupación medioambiental era a veces (o a menudo) dejada fuera, o al menos subestimada. Estimamos sin embargo que esa sustentabilidad del sistema de transporte ha sido reducida a menudo a una problemática a resolver por técnicos y por el empresariado. 
En el nivel urbano, la información sobre las condiciones del tránsito varía en los tres casos. El espacio para las interpretaciones locales o para otro desarrollo del transporte - distinto al estadounidense, orientado al automóvil- está limitado en el nivel urbano. Otras interpretaciones alternativas o locales dependen de la oposición pública o de una administración urbana fuerte (ejemplos de esto son Bogotá, Singapur y Copenhague).

Las contradicciones entre el primer y el segundo movimiento se hacen visibles en la administración urbana en el nivel correspondiente, pero también en el espacio de la calle. En este, los conflictos entre los vehículos motorizados y no motorizados son manifiestos. El tránsito es administrado, pero allí no hay intentos para buscar un acuerdo respecto de los problemas del sistema de transporte urbano en su conjunto. La ciudad de Copenhague puede ser vista como una excepción, por cuanto es la única que tiene un desarrollo para el transporte sustentable localmente basado. Actualmente, el tránsito urbano en Copenhague es el resultado de una secuencia de condiciones administrativas, deliberación pública, un movimiento ecologista fuerte y una temprana integración de la idea de sustentabilidad a la política nacional.

Este estudio muestra que los cambios políticos radicales, junto con el crecimiento económico y la modernización, están relacionados con la elaboración de las estrategias de transporte. En el caso de Teherán, el paso de una monarquía a una teocracia islámica cambió los planes de transporte urbano, pero luego de algunos años se pasó a un desorden similar al de otros países en vías de desarrollo. En Santiago, la instalación de un gobierno civil (una coalición demócrata cristiana) y el fin del régimen militar constituyeron el comienzo de una nueva era en la planificación del transporte. En Copenhague, los cambios políticos aparentemente fueron menos dramáticos, pero la introducción de la idea del desarrollo sustentable en la elaboración de políticas implicó un cambio importante en este ámbito, así como la introducción de planes de movilidad no motorizados.

Buscando aspectos genéricos del segundo movimiento protector de Polanyi, se pueden mencionar algunos elementos. Algunos grupos socio-económicos, particularmente los usuarios más vulnerables, no ejercen ninguna influencia sobre los procesos de planificación. Ellos pueden aparecer protestando (Chile) o pueden no hacerlo (Irán). A través del estudio, ha sido difícil encontrar fuentes confiables acerca de las actitudes o el comportamiento de la gente en relación con el desarrollo de los sistemas de transporte urbano. Cuando se pierde la perspectiva "desde abajo hacia arriba", se sigue la pérdida de información crucial acerca de cómo desarrollar el segundo movimiento. El desigual resultado social del aumento del tránsito se incrementa al mismo tiempo que una igualmente desigual distribución del ingreso. Estas condiciones insustentables han sido por largo tiempo dejadas fuera de la planificación operacional básica y de las evaluaciones en el nivel urbano. Pero sostenemos que, en orden a incrementar la sustentabilidad de los sistemas de transporte, se requiere conocimiento sobre los usuarios. Además, un conocimiento de esta naturaleza es crucial en la búsqueda de cambios sociales. Sin embargo, no hay suficiente conocimiento acerca del nivel micro.

Las políticas y la administración del tránsito entregan información sobre qué es considerado importante o deseable en una ciudad. Por tanto, las imágenes actuales del tránsito urbano no son reflejos objetivos de lo que está teniendo lugar. La manera en que los problemas son definidos emerge de las percepciones locales e internacionales. Así, éstos son socialmente construidos por las autoridades, y compartidos por un número de políticos, planificadores y otros. A este respecto, la hegemonía (o condiciones genéricas) se reproduce una y otra vez.

\subsection{Una mirada más cercana al mercado y el sector público en Teherán}

Comparadas con Copenhague y Santiago, las estrategias públicas y privadas relativas al tránsito urbano en Teherán parecían incluir pocas políticas asociadas con la sustentabilidad y la inversión pública. Al mismo tiempo, la teocracia iraní no era suficientemente transparente para permitir al observador decir algo definitivo acerca de la relación Estado-mercado y sus resultados en el diseño urbano o el transporte en Teherán. Ello no obstante, se observó cierto número de aspectos relacionados. Durante los 25 años de la revolución islámica ha habido ciertos cambios en la política, concernientes a la modernización y el crecimiento económico. El crecimiento en 
la motorización fue detenido por la revolución durante un tiempo, pero la Gran Teherán es hoy un área de rápida motorización, que disfruta de altos subsidios al combustible. El gobierno actual cambió las condiciones de mercado, y la motorización fue extendida en la misma dirección que en otros países. Sin embargo, la desigualdad económica fue agravada por una caída sustancial en el ingreso per cápita. Consecuentemente, la exclusión social resultó en una distribución del ingreso y un poder adquisitivo de viajes desigual. El gobierno fundamentalista parecía estar firmemente basado en las relaciones de poder tradicionales iraníes, y la gran industria manufacturera de vehículos permaneció en poder del Estado, En el futuro cercano, la producción del Paykan deberá competir con otros productores de automóviles extranjeros, invitados recientemente por el Estado iraní. Sin embargo, en 2003 el Estado aún controlaba la producción, importación y venta de automóviles, y estimulaba la conducción de éstos por medio de altos subsidios al petróleo. En 2003, las instancias del segundo movimiento regulatorio relativas al transporte urbano eran débiles y difíciles de descubrir en Irán. La cuestión de la administración del tránsito urbano motorizado no tenía prioridad en ningún nivel. Las oficinas encargadas de éste se enfocaban principalmente en problemas técnicos. Los recursos y la capacidad relacionada con el manejo del tránsito disfuncional estaban limitados, y el transporte público permanecía subdimensionado. No obstante, la contaminación del aire era vista como un problema importante. En el ámbito de la seguridad vial había algunos proyectos desarrollados junto con India y Alemania. Pero estas iniciativas tenían sólo efectos menores en relación con el rápido incremento de los vehículos motorizados y el caos presente en las calles de Teherán.

Irán no ha adoptado ninguno de los numerosos regímenes internacionales relativos a la Agenda 21 o a la Organización Internacional del Comercio. No hay nada parecido a las evaluaciones de impacto ambiental. Respecto al nivel de los hogares, no había audiencias públicas que desafiaran la actitud de los vecindarios, ni tampoco encuestas a los pasajeros o compilaciones de las opiniones de los usuarios que reflejaran las condiciones del transporte urbano. No había grupos cívicos trabajando con cuestiones medioambientales. Claramente, a este respecto ha- bía un déficit democrático y medioambiental en la administración urbana.

Tanto en Teherán como en Santiago, conducir un Mercedes o un SUV le entrega a su dueño tanto la privacidad que éste necesita como un atractivo prestigio social. Por muchas razones, el automóvil encaja en la vida social en Teherán como en cualquier otro lugar. Por ejemplo, a las mujeres se les permite moverse solas como conductoras en un automóvil privado, disfrutando su propio espacio separado que les da libertad y seguridad. Pero la motorización sigue las relaciones establecidas entre los sexos y se desarrolla dentro de las relaciones tradicionales de los géneros: una motorización masiva limitada refuerza las relaciones de género establecidas, dado que los hombres "entran" a la movilidad motorizada más rápido que las mujeres.

La emergente cultural del automóvil provoca probablemente menos resistencia en la Teherán de hoy que en las ciudades europeas, por cuanto allí no parece haber espacio para el debate público sobre el tema. Creemos que la aislada posición política de Irán (en relación con los países occidentales) tiene relación con la resistencia a desarrollar políticas operativas en el nivel urbano. Las restricciones a la utilización del automóvil provocan las mismas fuertes reacciones en Teherán que en todas partes.

La estrategia fundamentalista nacional islámica para el desarrollo social no parece estar reflejada en la política de transporte urbano, con la excepción de la separación de hombres y mujeres en los buses y vagones del metro. Los espacios separados para las mujeres aparecieron por primera vez en Estados Unidos, y han sido practicados, por ejemplo, en Tokio y Ciudad de México. Numerosas organizaciones de transporte se concentraron en el mejoramiento técnico, y se le dio prioridad a facilitar la motorización y las ampliaciones y a incrementar la eficiencia y los avances tecnológicos del sistema de transporte.

\subsection{Una mirada más cercana al mercado y el sector público en Santiago}

El caso de estudio de Santiago presenta una ciudad donde la administración del tránsito urbano está muy cercana a las oportunidades de negocios y -en general- a la modernización. Por ende, el trans- 
porte urbano es identificado como una importante estructura del gobierno de la ciudad. Las inversiones en infraestructura en Santiago son considerables, dado que ésta es percibida como una fuerza guía para el crecimiento económico. Actualmente, esta idea vertical es ampliamente aceptada. Paralelamente, los chilenos han aumentado sus expectativas de participación pública en política, pero también de mayores estándares de vida. Así, la percepción de cómo administrar la motorización depende de la cultura política preponderante, del gobierno y las preferencias populares. Sin embargo, en Chile la anterior negativa a controlar el transporte contribuyó a un sistema disfuncional. El fracaso del mercado en el manejo de las problemáticas del transporte y el tránsito fue evidente.

Durante los '90, la preocupación medioambiental nacional y el mensaje de la Agenda 21 recibieron atención formal. Se elaboró un programa, y se establecieron instituciones bajo la supervisión del presidente. Las políticas de modernización ecológica podrían ser descritas como procesos verticales "desde arriba hacia abajo", comenzados a instancias internacionales. En concordancia con esto, se estableció una nueva política a nivel macro. Sin embargo, en relación con los efectos secundarios de la motorización masiva no hubo demasiada atención pública. Chile tiene una población pequeña, y sólo una minoría es propietaria de automóviles. El entendimiento general parece ser que las emisiones contaminantes son muy bajas en Chile en relación con otros países, por lo que aparentemente -en términos generales- no son tomadas en serio por la gente. Esto indicaba que no era una preocupación general de los usuarios del transporte, en contraste con el "camino de la sustentabilidad" de Copenhague.

Cuando resumíamos los contenidos de las entrevistas en Santiago, no encontramos ningún cuestionamiento coherente sobre el nuevo plan para el sistema de Transporte. El objetivo del transporte sustentable era admitido positivamente por todos los entrevistados. Las ONG expresaban algunas críticas fundamentales al plan en su totalidad, particularmente en relación con los efectos secundarios sociales de la hegemonía del automóvil en el desarrollo urbano. La falta de un escenario público para intercambiar visiones acerca de las condiciones del tránsito y la planificación de la ciudad era sorprendente.
Muchas de las visiones presentadas por los entrevistados reflejaban el rol dominante del transporte en la búsqueda del crecimiento económico. Esta visión del progreso se transformaba en soluciones para el tránsito basadas en el automóvil. Por tanto, las respuestas reflejaban la meta comúnmente compartida de facilitar el crecimiento económico por medio del transporte motorizado. Se pronosticó que la cantidad de vehículos se incrementaría sustancialmente.

Sintetizando estas observaciones, la administración del transporte motorizado ya había comenzado, y había realizado un buen progreso. Las regulaciones estaban marchando con relación al transporte público de buses, pero no respecto de la utilización del automóvil privado - por ejemplo, la tarificación por congestión no era una opción política, según diversas fuentes. La administración urbana no estaba aún efectivamente coordinada para cubrir los diferentes intereses y necesidades. Desde nuestra perspectiva, el número de instituciones no era el factor decisivo, sino más bien cómo trabajaron, así como los objetivos de la administración. Esto revelaba parte de las tensiones inherentes entre el Estado/sector público y el mercado, concernientes a las complejas relaciones de la modernización ecológica, el crecimiento económico y las preferencias actuales entre los consumidores/votantes.

\subsection{Una mirada más cercana al mercado y el sector público en Copenhague}

En Copenhague ha habido variadas y enérgicas iniciativas políticas para aplicar el desarrollo sustentable en el transporte urbano, en contraste con la situación observada en Santiago y Teherán. El orden político en Dinamarca se reflejaba en la estructura establecida orientada a incrementar el transporte sustentable. Tal vez Copenhague era uno de los mejores ejemplos de doble movimiento en el sector del transporte. Este segundo movimiento regulatorio y protector era producto de las políticas de Estado y de una sociedad civil fuerte.

Sin embargo, las evaluaciones de políticas relativas a incrementar la sustentabilidad mostraban que los objetivos nacionales no se estaban alcanzando. Se requería mayores y más poderosos recursos, para "estimular una transición a modos de transporte menos contaminantes y más eficientes energéticamente" 
(Tengström, 1999, p. 73). En orden a conseguir un entendimiento de este cuadro aparentemente fragmentado, se requería cierta información de base.

En Dinamarca, a comienzos de los '90 los políticos se transformaron en importantes portadores del concepto clave de "sustentabilidad", así como de nociones como "medioambiente", "seguridad" y "calidad de vida". Una manera de implementar la sustentabilidad fue incrementando la capacidad estratégica, junto con indicadores de sustentabilidad demandados para medir el progreso. Esto incluía además un compromiso de largo plazo en línea con la Comisión Brundtland, lo que significaba la incorporación de objetivos presentados por políticas internacionales sobre el medioambiente. El propósito del plan de transporte fue "especificado en una serie de metas objetivas y cuantitativas: a) el consumo de energía del sector del transporte y las emisiones de $\mathrm{CO} 2$ de este sector deben ser estabilizadas antes del año 2005; b) la emisiones de NOx y HC debe ser reducidas al menos $40 \%$ antes de 2005 , y $60 \%$ antes de 2010; c) las emisiones de partículas deben ser reducidas a la mitad en pueblos y ciudades antes de 2010; y d) una reducción en los niveles de ruido en los habitantes expuestos a más de $55 \mathrm{~dB}$, al punto que al 2010, no más de 100.000 habitantes estén expuestos a más de 65 dB" (Tengström, 1999, p. 69). La modernización ecológica en Copenhague era una de las formas de integrar las políticas medioambientales con políticas de transporte, así como de armonizar las políticas danesas con las de la Unión Europea. En la investigación danesa, el concepto de administración del transporte ha sido aplicado al "proceso político de agenda setting, de formulación de políticas e implementación de decisiones en la práctica. La administración del transporte es efectuada por el Estado a diferentes niveles -nacional, regional y local- y abarca además todas las formas de interacción del Estado y la sociedad, y la manera en que ellas afectan las decisiones finales que son tomadas" (Figueroa, 2004). La comunidad científica danesa ha tenido además una voz en la formulación de políticas de transporte. En Copenhague hubo mucho más que una perspectiva "desde abajo hacia arriba”, incluyendo más instituciones establecidas haciendo uso de la opinión pública que en otras ciudades. Esta práctica consistió en una política institucional, incluyendo referéndum, panel de consenso y de expertos y debates públicos en la prensa y en la radio. Las redes cívicas operaban en "la sombra de la jerarquía del Estado” (Scharpf, 1999). Hubo además redes políticas estables alrededor de las diversas formas de deliberación pública y de las cuestiones sobre transporte que subrayaron la participación de diversos intereses del Estado. Los actores políticos, a diferentes niveles, interactuaron con el nivel micro por medio de deliberaciones y audiencias públicas. Concordantemente, se percibía a la sociedad civil trabajando "en los bordes de las instituciones formales y el gobierno" (Booher e Innes, 2000). Las intervenciones políticas tuvieron resultados tanto formales como informales.

Las variadas percepciones acerca de las estrategias para confrontar los problemas del primer movimiento pueden ser analizadas desde una variedad de perspectivas. En primer lugar, como se describe en un estudio comparativo de las políticas de transporte en un contexto europeo (danesas, alemanas y suecas), Tengström (1999) indica que las diversas estrategias nacionales para manejar los problemas del transporte están relacionadas con la cultura política y la historia local. La rápida respuesta a la Comisión Brundtland fue interpretada como el resultado de una combinación de factores, a saber: una falta de tradiciones institucionales para manejar el problema (dado que era una situación históricamente nueva) y la situación política verdaderamente dominante en aquel momento. En Dinamarca había un movimiento ecologista fuerte, considerado como la expresión de "las raíces populistas de la tradición de la cultura política danesa (Jamison et al. 1990, p. 192). La mayoría verde en el Parlamento estimuló la integración de la sustentabilidad medioambiental en varios sectores. El Plan de Acción de Transporte de 1990 puede ser visto como un resultado de esto (Tengström, 1999).

En 2003, la importancia de la escena pública parece haber llegado a su fin. En este punto, la Unión Europea reemplazó las políticas anteriores, y el ímpetu agobiante de la cultura del automóvil es evidente. Por ejemplo, dos de los movimientos sociales afirmaban estar en contra de la costosa construcción de infraestructura para automóviles, como autopistas, y de instalaciones subterráneas para estacionamientos de alto costo, por cuanto estas construcciones apoyaban el aumento de los viajes motorizados individuales. Los representantes percibían que sus 
argumentos eran dejados al margen por los decisores. La fuerza motorizada en el desarrollo social está genuinamente entrelazada a la principal corriente de modernización, en Dinamarca y en todas partes. Está también integrada a las políticas institucionales en la Unión Europea. Esta condición refleja la posición de un productor de automóviles que afirmó que "la sociedad tiene la principal responsabilidad de desarrollar nuestros sistemas de transporte" ${ }^{31}$.

\section{Conclusiones. Cómo enfrentarse a la movilidad motorizada en Copenhague, Santiago y Teherán}

Se ha dicho que el vigor de la cultura del automóvil como fuerza conductora de la modernización descansa en valores contemporáneos importantes. Ya a comienzos del siglo 20 el automóvil se transformó en un icono de la modernidad, dado que se correspondía bien con los valores centrales de la modernidad, a saber: libertad, movilidad, velocidad, individualismo, poder y privacidad.

La percepción del automóvil como un heraldo de la economía es genérica, y la hegemonía o cultura de éste no ha sido refutada por los actores dominantes, sino más bien estimulada por el carácter (o la pérdida) del contrato social en algunas economías liberales de países en vías de desarrollo. Esta es una de las razones por las cuales la motorización masiva no es controlada, sino apoyada y estimulada. Hay muy pocos ejemplos donde los políticos nacionales se han opuesto a la automovilización masiva $\left(\right.$ Thynell, 2004) ${ }^{32}$. Hasta ahora, las políticas de restricción al automóvil han sido expresiones de gobiernos no liberales, de estancamiento económico o de contextos de bajos ingresos ${ }^{33}$.

${ }^{31}$ Discurso del Director de Administración de la Volvo Car Corporation, Hans-Olov Olsson, en el Future Urban Transport Congress (Gotemburgo, 22 de septiembre de 2003).

${ }^{32}$ Cuba e Irán son dos ejemplos de países que se han opuesto oficialmente a extender el uso de los automóviles privados durante ciertos periodos.

${ }^{33}$ Entre los países donde la propiedad o utilización del automóvil ha sido restringida por razones económicas o políticas se cuentan Noruega, Albania, China, Japón y las antiguas repúblicas soviéticas, junto con los países de Europa central.
Una forma común de percibir el desarrollo es que el "progreso verdadero" está basado en el ímpetu de la cultura del automóvil y en sistemas tecnológicos costosos y extensos como el metro. Además, parece haber una falta de conocimiento acerca de soluciones de largo alcance, lo que lleva a los políticos a imitar lo que se hace en Estados Unidos, como si eso fuera de facto una referencia para el progreso. La forma de administrar el tránsito y las problemáticas del transporte en ese país son un reflejo de su orden político, y el contrato social es muy diferente del de Irán, Chile o Dinamarca. Por tanto, la forma liberal e individual de desarrollar la movilidad en Estados Unidos no puede ser vista como un modelo incontestado o tomado como garantía fuera de aquel.

Los efectos en las propiedades, el reforzamiento de la expansión urbana, los comportamientos sociales y los estilos de vida parecen ser genéricos. El progreso de la modernización y los dramáticos incrementos de la movilidad física han rediseñado la forma entera de estas tres ciudades. En Teherán, el reemplazo de la infraestructura de las antiguas formas de vida (casas y calles tradicionales) y la planificación urbana actual se ajusta a una cultura del automóvil en expansión. La introducción de calles peatonales en Copenhague ha reestructurado la economía política del centro de la ciudad, incluyendo un incremento sustancial de los precios en muchos aspectos de la vida. En Santiago, la presencia de vehículos y de congestión, incluyendo la construcción de varias autopistas en la ciudad, produce los mismos cambios sociales que en otras ciudades. Las medidas amistosas hacia el automóvil que facilitan el flujo de éstos y de vehículos pesados parecen no estar confrontadas con un genuino concepto del desarrollo urbano en Santiago o Teherán. Mientras tanto, en Copenhague el municipio intenta alcanzar la noción de una ciudad con calidad de vida, que resulta atractiva además para la vida familiar.

Esta experiencia de investigación apoya la percepción de que hoy las alternativas de viaje no motorizadas y menos costosas no reciben por lo general inversiones importantes, y sólo ocasionalmente la infraestructura no motorizada es hecha de manera más segura y confortable. En lugar de esto, los medios de transporte más caros y más avanzados tecnológicamente son favorecidos por la iniciativa política y el apoyo económico. Consecuentemente, la por- 
ción de viajes motorizados está creciendo. Parte de este crecimiento consiste en viajes realizados en automóviles privados o radio taxis, como en el caso de Teherán, o en "colectivos" y radio taxis, como en Santiago. Estos viajes privados organizados están a menudo más allá del control de las autoridades. Esta tendencia y sus diferentes rasgos -legales e ilegalesparecen ser genéricos en muchas ciudades, pero no en Copenhague. En Santiago y Teherán, la gente (a menudo hombres de bajos ingresos) busca alternativas de movilidad tales como taxis ilegales, radiotaxis, "colectivos" u otras formas de viajar junto con otras personas en un automóvil privado. Estos automóviles pueden ser de propiedad privada, y suministran las llamadas formas para-organizadas de movilidad urbana. Hay otros medios legales, como los "colectivos" en Santiago. En las ciudades donde la planificación no ha considerado las necesidades de todos los habitantes, estos tipos de soluciones populares parecen ganar en importancia. Este estudio muestra que cada ciudad organiza y maneja las problemáticas urbanas (viajes legales/ilegales) de manera diferenciada, dependiendo de las consideraciones sociopolíticas y de las maneras de enfrentar las dificultades. Lo que se percibe como regulaciones políticamente viables depende de la ciudad en que se viva.

Por lo tanto, la respuesta a la pregunta introductoria acerca de las posibilidades de abrir una nueva ventana de posibilidades relativa a formas de mejorar el transporte urbano es sí, con la reserva de que esta ventana está sólo ligeramente abierta. Las políticas de transporte urbano están influenciadas por la acentuada globalización, así como por los problemas definidos localmente. Es más probable que las nuevas estrategias se desarrollen como respuesta al deterioro medioambiental y a los crecientes problemas de abastecimiento de energía. Los investigadores del transporte y los administradores más importantes en varias ciudades en desarrollo siguen de cerca la investigación realizada en Estados Unidos. Esto es sorprendente, toda vez que las condiciones de las ciudades en el resto del mundo son diferentes a la experiencia en las ciudades estadounidenses.

La percepción dominante sobre la modernización y el crecimiento aún no tolera fuertes ataques a la cultura del automóvil. Por lo tanto, las políticas de transporte sustentable orientadas a la regulación de la motorización masiva estarán en conflicto con los rasgos genéricos de la cultura del automóvil. A pesar de la adopción global y nacional de la noción de desarrollo sustentable, se requiere una fuerte voluntad política a nivel urbano para incrementar la sustentabilidad en la ciudad, como se ha mostrado en Curitiba, Bogotá y Londres. Los sistemas no motorizados, más baratos y de baja tecnología como los buses, la caminata y la bicicleta, son percibidos como formas de transporte menos desarrolladas que finalmente desaparecerán, en tanto continúen el crecimiento económico y la modernización. Concordantemente, no reciben mucha atención ni inversiones costosas. Así, en ciudades en expansión donde la modernización económica (Santiago) y el mejoramiento tecnológico (Teherán) tienen prioridad, el proceso de exclusión social parece genérico y -en algunas circunstancias- incluso reforzado por la motorización masiva.

Otra conclusión es que las regulaciones han sido comúnmente aceptadas en países donde el Estado tiene un alto grado de legitimidad. La aceptación o resistencia/desobediencia de las reglas del tránsito o de la administración del transporte se relaciona con el contrato social existente; ¡la sociedad opta por soluciones públicas basadas en visiones colectivas o los votantes buscan soluciones individuales a las necesidades diarias de movilidad? En Santiago, las estrategias se basan en contribuciones privadas y colectivas, y cuentan con muchos menos recursos públicos que en Copenhague. En esta ciudad, los cambios estructurales de la administración política, un nuevo gobierno y la transformación social, junto con fuertes redes sociales, sientan las bases de una solución win-win consistente en una nueva ventana de posibilidades. Aquí, el transporte sustentable fue adoptado como un objetivo político hace largo tiempo. Las estrategias adoptadas tuvieron un resultado diferente, a saber, el de desarrollar una política de transporte urbano inspirado en la Agenda 21. Además, se aplicó deliberación pública.

El establecimiento de calles peatonales (hace 40 años) y de muchas vías para bicicletas ha sido un éxito. En Copenhague, un porcentaje importante de los viajes se realiza a través de medios no motorizados, y una política consciente de apoyo a los ciclistas ha mejorado además las condiciones de los peatones en la ciudad. Este caso de estudio revela que una nueva agenda de transporte puede tener lugar en 
ocasiones especiales, dada por cambios o crisis sociopolíticas. En otros casos, el "embrollo usual" ha dominado y las nuevas agendas emergen muy lentamente.

Otra debilidad comúnmente compartida -aparentemente universal- es la coordinación subdesarrollada de las diversas instituciones involucradas en la administración del transporte urbano. El caso de Copenhague enfatiza la importancia de actividades coordinadas y de largo plazo. En términos de Polanyi, esto puede ser analizado desde la perspectiva de un segundo movimiento desarrollado y vital, influenciado por tres áreas de la sociedad: el Estado, el mercado y la sociedad civil. Esta colaboración fue exitosa y proactiva en relación con los aspectos negativos de la modernización de la motorización (como el caos en el tránsito urbano). En Santiago y Teherán encontramos iniciativas reactivas y más aisladas. Consecuentemente, el resultado de estas intervenciones aisladas es una modernización urbana desigual, un diseño urbano fragmentado debido a la falta de un plan urbano integrado, y menos igualamiento de las diferencias socio-económicas.

Nuestros estudios anteriores de ciudades capitales (Santiago, Teherán, Brasilia, Nueva Delhi y Roma) muestran que la administración del tránsito urbano a menudo reafirma estructuras sociales desiguales, a pesar de los objetivos declarados de apoyar lo contrario. Hasta ahora, los intentos de resolver los desafíos medioambientales no han incluido nuevos grupos de poder en la administración urbana. En estas tres ciudades las relaciones políticas y económicas establecidas no se encuentran desafiadas por las preocupaciones medioambientales. Las políticas ambientales globales no hacen frente al orden político tradicional establecido (Thynell, 2003) ${ }^{34}$. Por tanto, esto ha fortalecido en general la posición del empresariado. Respecto de las políticas medioambientales globales, numerosos y variados regímenes internacionales destacan el valor y la importancia de la participación pública, desde la Convención Aarhus (1988) a la Declaración de Río (1992). En las relaciones europeas, esto puede ser visto en las decisiones de la Unión Europea

\footnotetext{
${ }^{34}$ El Consejo Mundial de Negocios para el Desarrollo Sustentable (WBCSD) es un poderoso actor en el ámbito de la motorización, con la afiliación global de 150 importantes productores.
}

sobre la evaluación de impacto ambiental (2000) y la evaluación ambiental estratégica (2001). Estas declaraciones son expresión de intervenciones políticas, y como tales, parte del segundo movimiento protector.

Los numerosos intentos por vincular los Objetivos de Desarrollo del Milenio del Banco Mundial con el sector del transporte han estado dirigidos principalmente a decisiones en el nivel nacional. Pero el desarrollo social requiere también la movilización e interacción con el nivel micro. Una forma de lograr el crecimiento económico puede ser integrando los supuestos de los programas de reducción de pobreza en las políticas de transporte urbano. Todavía la reducción de la pobreza y la sustentabilidad se perciben fundamentalmente como objetivos nacionales. Hasta ahora, estas políticas no funcionan sin un entendimiento de las dinámicas a nivel del usuario. Por ende, es tiempo de desanudar el discurso de los economistas en orden a fundamentar el desarrollo en otros conceptos y entender el potencial del cambio a través de un transporte sustentable. Las diversas estrategias de los actores podrían ser también analizadas desde la perspectiva de las relaciones estructurales en el nivel nacional, en orden a tener una comprensión más completa de las relaciones domésticas de poder, y explorar políticas de transporte urbano viables.

\section{Referencias bibliográficas}

Abrahamian, E. (1982). Iran between two revolutions. New Jersey: Princeton University Press.

Booher, D. y J. Innes (2000). "Public participation in planning: New strategies for the 21th century". Working Paper 2000-7. Berkley: Institute of Urban Regional Developoment, University of California at Berkley.

Bøgelund, P., H. Hansen, C. Tengström y E. Hedegaard Sørensen (2002). "Baeredygtig transport-Perspektiver fra forskningen”. Notat nr 02.03. København: Transportrådet.

City of Copenhagen. (2001). Copenhagen-city of cyclists bicycle. Account 2000. Copenhagen: Building and Construction Administration.

Figueroa, M.J. (2004). "Public participation, democracy and environmental integration in transport: Can EIA/SEA provide a feasible 
Modernidad en movimiento. Cómo enfrentarse a la movilidad motorizada en Teherán, Santiago y Copenhague

connection?". Planning for Sustainable Development: The Practice and Potential of Environmental Assessment. Stockholm: Nordregio.

Jamison, A.E., R. Cramer y J. Lassøe (1990). The making of the new Environmental Conciousness: A comparative study of the environmental movements in Sweden, Denmark and the Netherlands. Edinburgh: Edinburgh University Press.

Københavns Kommune. (2002). Trafik-og miljøplan 2003 Status of hovedproblemer-grundlag for debat. Århus: Økonomiforvaltningen.

Lindblom, C. (1977). Politics and markets. New York: Basic Books.

Lundqvist, L. (1996). "Sweden". Munk Christiansen, P. (ed.), Governing the environment: Politics, policy, and organisation in the Nordic countries. Oslo: Nordic Council of Ministers.

Madanipour, A. (1998). "Tehran: The making of a metropolis”. Johnston, J.R. y P.L. Know (eds.), World cities series. Chichester: John Wiley \& Sons.

Ministry of the Environment (2002). Spatial planning in Denmark. Copenhagen: Spatial Planning Department.

O'Ryan, R. y T. Turrentine (2000). Greenhouse gas emissions in the transport sector 2000-2020: Case study for Chile. Davis, CA: University of California at Davis.

Polanyi, K. (1957). The great transformation. Boston: Beacon Press.
Sassen, S. (2002). Global networks, linked cities. London: Routledge.

SECTRA (2003). Actualización de encuestas origen destino de viajes. Vetapa. Santiago: SECTRA.

Scharpf, F. (1999). Governing in Europe. Oxford: Oxford University Press.

Sperling, D.D. y M. O'Ryan (2002). Transportation in developing countries: Greenhouse gas scenarios for Santiago. Arlington VA: Pew Climate Organization.

Tehran Comprehensive Transportation \& Traffic Studies (2002). Metropolitan Tehran Transportation and traffic information. Tehran: TCTTS.

Tengström, E. (1999). Towards environmental sustainability? A comparative study of Danish, Dutch and Swedish transport policies in a European context. Aldershot: Ashgate Publishing Company.

The World Bank (2001). Chile: poverty and income distribution in a high growth economy. The case of Chile, 1987-1998. Washington, DC: The World Bank.

Thynell, M. (2003). The unmanageable modernity. An explorative study of motorized mobility in development. Ph.D. Thesis, Department of Peace and Development Research, Göteborg University. Göteborg: Vasastadens Bokbinderi. (2004). "Managing modern urban mobility systems from the perspective of social science". The XI World Congress of Urban Transport (CODATU). Rotterdam: Balkema Publishers. 